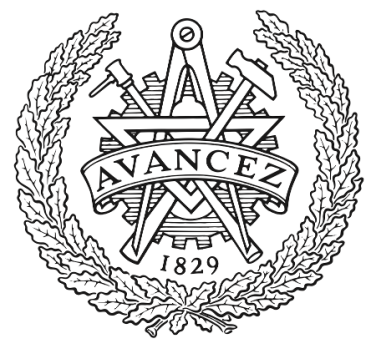

CHALMERS

UNIVERSITY OF TECHNOLOGY

\title{
Synthesis of Palladium Nanodendrites Using a Mixture of Cationic and Anionic Surfactants
}

Downloaded from: https://research.chalmers.se, 2023-04-26 10:52 UTC

Citation for the original published paper (version of record):

Wen, X., Lerch, S., Wang, Z. et al (2020). Synthesis of Palladium Nanodendrites Using a Mixture of Cationic and Anionic Surfactants. Langmuir, 36(7): 1745-1753.

http://dx.doi.org/10.1021/acs.langmuir.9b03804

N.B. When citing this work, cite the original published paper. 


\title{
Synthesis of Palladium Nanodendrites Using a Mixture of Cationic and Anionic Surfactants
}

\author{
Xin Wen, Sarah Lerch, Zhihang Wang, Bassem Aboudiab, Ali Reza Tehrani-Bagha, Eva Olsson, \\ and Kasper Moth-Poulsen*
}

Cite This: Langmuir 2020, 36, 1745-1753

Read Online

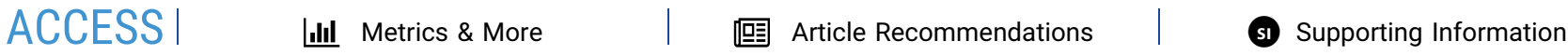

ABSTRACT: Surfactants are used widely to control the synthesis of shaped noble-metal nanoparticles. In this work, a mixture of hexadecyltrimethylammonium bromide (CTAB), a cationic surfactant; sodium oleate $(\mathrm{NaOL})$, an anionic surfactant; palladium chloride; and a reducing agent were used in the seed-mediated synthesis of palladium nanoparticles. By controlling the surfactant mixture ratio, we initially discovered that palladium nanodendrites with narrow size distribution were formed instead of the traditional nanocubes, synthesized with only CTAB. In order to investigate the optimal ratio to produce $\mathrm{Pd}$ nanodendrites with a high yield and narrow size distribution, samples synthesized with multiple molar ratios of the two surfactants were prepared and studied by transmission electron microscopy, dynamic light scattering, conductance, and ultraviolet-visible spectroscopy. We propose that the addition of $\mathrm{NaOL}$ alters the arrangement of surfactants

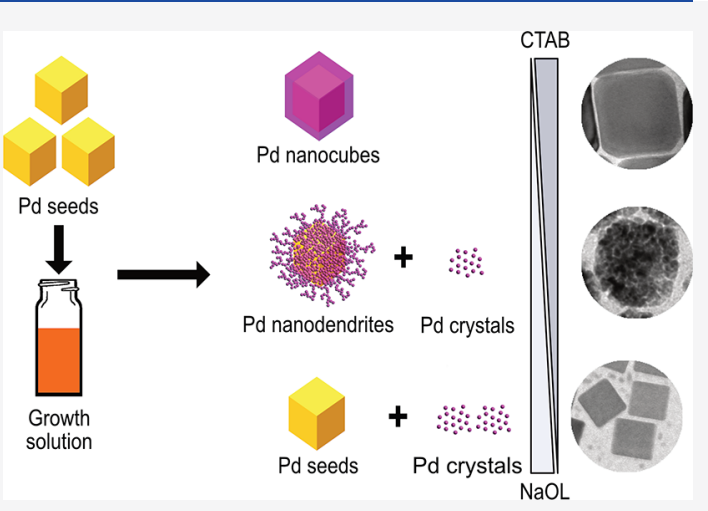
on the Pd seed surface, leading to a new pattern of growth and aggregation. By studying the nanodendrite growth over time, we identified the reduction period of $\mathrm{Pd}^{2+}$ ions and the formation period of the nanodendrites. Our further experiments, including the replacement of CTAB with hexadecyltrimethylammonium chloride (CTAC) and the replacement of NaOL with sodium stearate, showed that $\mathrm{CTA}^{+}$ions in $\mathrm{CTAB}$ and $\mathrm{OL}^{-}$ions in $\mathrm{NaOL}$ play the main roles in the formation of nanodendrites. The formation of palladium nanodendrites was robust and achieved with a range of temperatures, $\mathrm{pH}$ and mixing speeds.

\section{INTRODUCTION}

Palladium (Pd) nanoparticles have attracted considerable interest due to their hydrogen uptake ability and effective catalytic activity leading to a variety of applications, including catalysis, gas sensing, and hydrogen storage. ${ }^{1-4}$ In most hydrogen-based applications, the hydrogen atoms initially dissociate on the surface of $\mathrm{Pd}$. In sensing or storage applications, the hydrogen atoms diffuse into the subsurface layers, forming a Pd hydride. ${ }^{3,5,6}$ In catalytic applications, the dissociated hydrogen atoms are capable of quickly reacting with the other reactants to increase the reaction rate. Since the initial dissociation of the hydrogen atoms is surface-dependent, increasing the accessible surface area of Pd nanoparticles will result in a corresponding increase in the catalytic performance. Additionally, dissociation rates of hydrogen vary with the crystal facets. $^{7-9}$ Therefore, the shape of Pd nanoparticles is expected to expose the crystal facets that promote faster dissociation on the surface, and the synthesis of $\mathrm{Pd}$ nanoparticles with large surface area is becoming relevant for sensing and catalytic applications.

Nanoparticles can be synthesized in a variety of methods, including atomic deposition, electron beam lithography, laser ablation, and colloidal synthesis. ${ }^{10-12}$ Although many of these methods have their own distinct advantages, colloidal methods can allow for straightforward synthesis of uniquely shaped, mono- or polycrystalline nanoparticles. One of the most common colloidal methods is seed-mediated growth, which can synthesize cubic, octahedral, rhombic, or dodecahedral Pd nanoparticles. ${ }^{1,2,13-16}$

The seed-mediated growth method is a versatile and efficient method for synthesizing high-quality metallic nanoparticles. $^{17,18}$ This method has some interesting features: (a) particle size and shape can be controlled, (b) the reaction rate is relatively fast when close to room temperature, (c) the experimental process is typically simple and inexpensive, and (d) core-shell particles can be synthesized. ${ }^{19-22}$ In a typical seed-mediated growth synthesis, the nucleation of metallic crystal seeds starts with a rapidly occurring reduction reaction, resulting in a high concentration of tiny metallic seeds. Then, the seed solution is injected into a growth solution, which supplies the necessary reagents for the seeds to grow into larger nanoparticles. ${ }^{19,23}$ This growth process can be repeated in

Received: December 11, 2019

Revised: February 6, 2020

Published: February 7, 2020 
multiple, short steps with new growth solutions for each step to grow the nanoparticles slowly, or the process can happen in one, more concentrated, growth solution over a longer period of time, through a process such as Ostwald ripening. ${ }^{24,25}$ Generally, a metal salt, a reducing agent, and a capping agent are necessary in both seed and growth solutions. ${ }^{26}$ The metal salts supply the additional metallic ions necessary for the effective, controllable growth of the nanoparticles, while the reducing agent converts these metallic ions into atoms and can be used to control the speed of growth by limiting the accessibility of the newly reduced metal atoms. Capping agents, such as surfactants, polymers, ligands, or dendrimers, are employed to promote the stability of the nanoparticles but are also used to control the size and shape of nanoparticles. ${ }^{19,27,28}$ Changing the type and concentration of capping agents can result in the growth of nanoparticles with specific shapes, primarily through the stabilization of specific facets of the nanoparticle crystal structure. ${ }^{29}$

Hexadecyltrimethylammonium bromide (CTAB), a cationic surfactant with a C16 alkyl tail and a quaternary ammonium head group, has been widely used as a capping agent in the synthesis of gold, silver, and Pd nanoparticles. ${ }^{2,10,30}$ CTAB molecules bind strongly to the surface of metal nanoparticles, typically forming a bilayer of surfactant, and the presence of the bromide $\left(\mathrm{Br}^{-}\right)$ion stabilizes specific facets of these nanoparticles. $^{31}$ Isotropic or anisotropic growth of nanoparticles can be achieved by adjusting the concentration of $\mathrm{CTAB}$ or the $\mathrm{pH}$ of the growth solution. ${ }^{29,31}$ Additionally, $\mathrm{CTAB}$ enhances the stability of the metal nanoparticle dispersion (i.e., prevents their aggregation) by increasing the electrostatic repulsion between the particles. ${ }^{31,32}$ However, in the typical seed-mediated synthesis of Pd nanoparticles with only $\mathrm{CTAB}$, limited shapes of Pd nanoparticles can be obtained. ${ }^{2,33}$ In order to synthesize Pd nanoparticles with a shape that has a large surface area, we have modified the traditional seed-mediated method. For the first time, a binary surfactant mixture of $\mathrm{CTAB}$ and sodium oleate $(\mathrm{NaOL})$, two surfactants with oppositely charged head groups, is applied in the synthesis of $\mathrm{Pd}$ nanoparticles. $\mathrm{NaOL}$ is an anionic surfactant with a double bond in its long hydrocarbon chain. When $\mathrm{CTAB}$ and $\mathrm{NaOL}$ are mixed in water, the mixture has a critical micelle concentration (CMC), critical packing parameter (CPP), and other physical properties different from those of a pure CTAB or $\mathrm{NaOL}$ solution. ${ }^{34,35}$ Additionally, based on theories of mixed surfactants and surfactant adsorption on solid surfaces, ${ }^{36}$ mixing hexadecyltrimethylammonium ions $\left(\mathrm{CTA}^{+}\right)$and oleate ions $\left(\mathrm{OL}^{-}\right)$leads to a more complicated surfactant distribution on metal nanoparticle surfaces. ${ }^{34}$ Therefore, NaOL mixed with CTAB is predicted to significantly change the performance of the surfactants in a seed-mediated growth method. Previously, these binary surfactants have been applied to a seed-mediated gold nanorod synthesis, resulting in an increased yield and quality of gold nanorods. ${ }^{37-39}$

In this paper, for the first time, synthesis of $\mathrm{Pd}$ nanodendrites was achieved by controlling the molar ratio of CTAB and $\mathrm{NaOL}$ in surfactant mixtures. These $\mathrm{Pd}$ nanodendrites feature large surface areas, which have the potential to improve the material efficiency of Pd nanoparticles in sensing and catalytic applications. Huang and co-workers ${ }^{40}$ previously studied gold-palladium core-shell nanodendrites synthesized by a mixture of CTAB and 5-bromosalicylic acid for similar applications; however, the formation mechanism of the nanodendrites is still unclear and may be dependent on the surfactants used. In our work, a binary surfactant mixture was used instead of the mixture of a surfactant and acid. Additionally, $\mathrm{CTAB}$ is the only source of $\mathrm{Br}^{-}$ions, which makes it possible to study the mechanism of the dendritic formation.

We identified the optimal molar ratio for the surfactants that promotes the formation of Pd nanodendrites with high yield and narrow size distribution. Further experiments were set to replace $\mathrm{CTAB}$ and $\mathrm{NaOL}$ by hexadecyltrimethylammonium chloride (CTAC) and sodium stearate $(\mathrm{NaST})$, respectively, to investigate the contributions of the surfactants to the mechanism of the Pd nanodendrite formations. Additionally, the growth process of $\mathrm{Pd}$ nanodendrites on the seed surface was monitored over a period of $14 \mathrm{~h}$. Finally, the effects of other parameters, such as the stirring speed, temperature, and $\mathrm{pH}$, on the shape of $\mathrm{Pd}$ nanoparticles were studied to ensure robust dendrite formation.

On the basis of these studies, a model is proposed to explain the growth of $\mathrm{Pd}$ nanoparticles in growth solutions with different $\mathrm{CTAB}$ molar ratios, as depicted in Figure 1. When

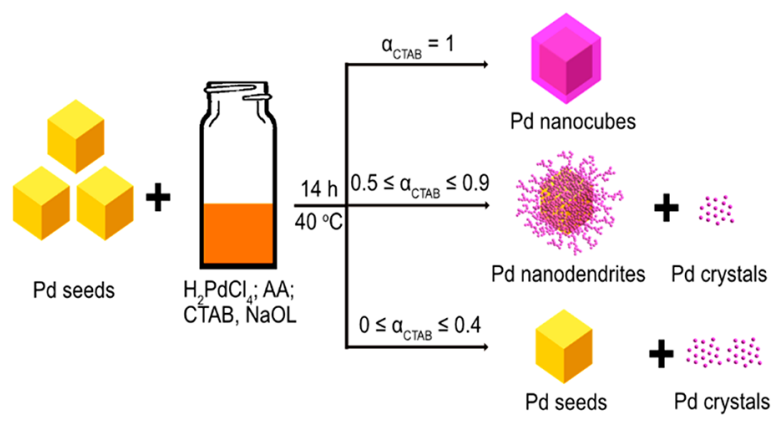

Figure 1. Schematic illustration of the shapes of $\mathrm{Pd}$ nanoparticles grown with different $\alpha_{\mathrm{CTAB}}$ values, AA is L-Ascorbic Acid.

there is only $\mathrm{CTAB}\left(\alpha_{\mathrm{CTAB}}=1\right)$, Pd cubic seeds grow into larger Pd nanocubes; when $0.5 \leq \alpha_{\text {СТAB }} \leq 0.9$, Pd nanodendrites and a few $\mathrm{Pd}$ crystals are formed; when $0 \leq$ $\alpha_{\text {CTAB }} \leq 0.4$, small Pd crystals are obtained and Pd seeds are not able to grow further. This model identifies the micellar formation of the surfactants in solution as the reason for this dramatic shape change.

\section{EXPERIMENTAL SECTION}

Materials. Hexadecyltrimethylammonium bromide (CTAB, $\geq 99 \%$ ), sodium stearate (NaST, $\geq 99 \%)$, L-ascorbic acid (AA, $\geq$ $99 \%)$, palladium(II) chloride $\left(\mathrm{PdCl}_{2}, 99.999 \%\right)$, and sodium hydroxide $(\mathrm{NaOH}, \geq 97.0 \%)$ were purchased from Sigma-Aldrich. Sodium oleate $(\mathrm{NaOL},>97.0 \%)$ and hexadecyltrimethylammonium chloride (CTAC, $>95.0 \%$ ) were obtained from Tokyo Chemical Industry. Hydrochloric acid ( $\mathrm{HCl}, 37 \mathrm{wt} \%$ in water) was purchased from VWR Chemicals. All solutions were prepared with ultrapure water $(18.2 \mathrm{M} \Omega)$, which is purified with a Milli-Q Advantage A10 water purification system from Merck. Additionally, a $10 \mathrm{mM}$ $\mathrm{H}_{2} \mathrm{PdCl}_{4}$ solution was prepared by dissolving $0.1773 \mathrm{~g}$ of $\mathrm{PdCl}_{2}$ in 10 $\mathrm{mL}$ of $0.2 \mathrm{M} \mathrm{HCl}$ solution and then diluting to $100 \mathrm{~mL}$ with ultrapure water. ${ }^{1} \mathrm{CTAB}$ and $\mathrm{NaOL}$ aqueous solutions were stored in a water bath at $40{ }^{\circ} \mathrm{C}$. Fisherbrand EPA screw neck glass vials $(20 \mathrm{~mL})$ were used for preparing the solutions. Glassware and magnetic stir bars were washed by freshly prepared aqua regia $(3: 1$ volume of $\mathrm{HCl}$ and $\mathrm{HNO}_{3}$ ) prior to use.

Synthesis of Pd Nanodendrites. The synthesis of the Pd nanodendrites was initially adapted from ref 2 , for the synthesis of Pd 
Table 1. Summary of the Seed-Mediated Growth Synthesis Experiments ${ }^{a}$

\begin{tabular}{|c|c|c|c|c|c|}
\hline$\alpha_{\mathrm{CTAB}}{ }^{b}$ & $V_{\mathrm{CTAB}}, \mathrm{mL}$ & $V_{\mathrm{NaOL}}, \mathrm{mL}$ & $\zeta$-potential, $\mathrm{mV}$ & conductance, $\mathrm{mS} / \mathrm{cm}$ & yield of $\mathrm{Pd}$ nanoparticles, $\mathrm{mg} / \mathrm{mL}$ \\
\hline 1 & 5 & 0 & $60.9 \pm 5.9$ & 1.25 & 0.057 \\
\hline 0.9 & 4.5 & 0.5 & $55.6 \pm 11.0$ & 1.52 & 0.073 \\
\hline 0.8 & 4 & 1 & $38.9 \pm 1.6$ & 1.75 & 0.057 \\
\hline 0.7 & 3.5 & 1.5 & $37.5 \pm 1.2$ & 2.04 & 0.047 \\
\hline 0.6 & 3 & 2 & $36.2 \pm 7.2$ & 2.13 & 0.043 \\
\hline 0.5 & 2.5 & 2.5 & $8.66 \pm 5.9$ & 1.96 & 0.04 \\
\hline 0.4 & 2 & 3 & $-68.6 \pm 0.9$ & 2.4 & 0.127 \\
\hline 0.3 & 1.5 & 3.5 & $-73.8 \pm 1.0$ & 2.09 & 0.117 \\
\hline 0.2 & 1 & 4 & $-78.8 \pm 7.1$ & 1.86 & 0.057 \\
\hline 0.1 & 0.5 & 4.5 & $-78.4 \pm 8.8$ & 1.56 & 0.063 \\
\hline 0 & 0 & 5 & $-58.3 \pm 0.9$ & 1.35 & 0.023 \\
\hline
\end{tabular}

${ }^{a} \mathrm{~A}$ mixture of $\mathrm{CTAB}$ and $\mathrm{NaOL}$ was used for the preparation of the growth solution. The initial concentration of the surfactants was $[\mathrm{CTAB}]=$ $[\mathrm{NaOL}]=50 \mathrm{mM}$. The $\zeta$-potential and conductance of the mixture were measured at $40{ }^{\circ} \mathrm{C} .{ }^{b} \alpha_{\mathrm{CTAB}}$ is the molar ratio of CTAB and binary surfactant mixture. There is only CTAB at $\alpha_{\mathrm{CTAB}}=1$ and only $\mathrm{NaOL}$ at $\alpha_{\mathrm{CTAB}}=0$.

nanocubes, and ref 37 , where a similar surfactant mixture was used to form gold nanorods.

Seed Solution. Ten milliliters of $12.5 \mathrm{mM} \mathrm{CTAB}$ was transferred to a $20 \mathrm{~mL}$ glass vial in an oil bath at $95{ }^{\circ} \mathrm{C}$, while being stirred at an apparent speed of $400 \mathrm{rpm}$. Then, $0.5 \mathrm{~mL}$ of $10 \mathrm{mM} \mathrm{H}_{2} \mathrm{PdCl}_{4}$ was added to the CTAB solution. After $5 \mathrm{~min}, 80 \mu \mathrm{L}$ of $100 \mathrm{mM}$ AA was injected into the $\mathrm{CTAB}-\mathrm{Pd}$ solution, with continuous stirring. The solution was incubated at $95{ }^{\circ} \mathrm{C}$ for $30 \mathrm{~min}$ before use. A fresh seed solution was prepared for each synthesis process due to the degradation of the seeds a few hours after preparation.

Growth Solution. Solutions of $50 \mathrm{mM}$ CTAB and $50 \mathrm{mM} \mathrm{NaOL}$ were added in different volume proportions and mixed well to obtain a mixture with a total volume of $5 \mathrm{~mL}$. The mixture was stored in a 20 $\mathrm{mL}$ glass vial at room temperature. Respective $\mathrm{CTAB}$ and $\mathrm{NaOL}$ volumes and molar ratios are shown in Table 1 . After that, $125 \mu \mathrm{L}$ of $10 \mathrm{mM} \mathrm{H}_{2} \mathrm{PdCl}_{4}, 200 \mu \mathrm{L}$ of fresh seed solution, and $25 \mu \mathrm{L}$ of $100 \mathrm{mM}$ AA were added, in this order, to the surfactant solution and mixed thoroughly on a vortex (Scientific Industries Vortes Genie 2) after each addition. The mixture was then kept in a water bath at $40{ }^{\circ} \mathrm{C}$ for $14 \mathrm{~h}$ without stirring. The final growth solution was centrifuged (VWR Micro Star 12) at $2400 \mathrm{RCF}(6000 \mathrm{rpm})$ for $20 \mathrm{~min}$. A specific volume of ultrapure water, determined by the application of the nanodendrites, was added after removing the supernatant.

In order to tune the $\mathrm{pH}$ value of the growth solution, $13.75 \mu \mathrm{L}$ of 1 $\mathrm{M} \mathrm{HCl}$ or $5 \mu \mathrm{L}$ of $1 \mathrm{M} \mathrm{NaOH}$ solution was injected after adding the seed solution but before addition of AA.

Characterization. Morphologies of $\mathrm{Pd}$ nanoparticles were investigated with a FEI Tecnai T20 transmission electron microscope (TEM) at $200 \mathrm{kV}$ and an FEI Titan 80-300 TEM at $300 \mathrm{kV}$. The $\zeta$ potential was studied with a Malvern Panalytical Zetasizer Nano ZS. The absorbance spectra were measured on an Agilent Cary 60 ultraviolet-visible (UV-vis) spectrophotometer with a xenon flash lamp $(80 \mathrm{~Hz})$ as a light source. A Metrohm 856 conductivity module was used to measure the solution conductance. A Jenway $570 \mathrm{pH}$ meter was used to measure the $\mathrm{pH}$ value of the solutions.

\section{RESULTS AND DISCUSSION}

In order to study the effect of the binary surfactant mixture on the shape and yield of Pd nanoparticles, a series of seedmediated growth synthesis experiments were performed with different molar ratios of $\mathrm{CTAB}$ and $\mathrm{NaOL}$ but maintaining the same total volume and initial molar concentrations of the surfactants $(50 \mathrm{mM})$. The volumes of the surfactants added in the growth solution for each batch are shown in Table 1. The amount of $\mathrm{CTAB}$ decreases, and consequently, the amount of $\mathrm{NaOL}$ increases from $\alpha_{\mathrm{CTAB}}=1$ to $\alpha_{\mathrm{CTAB}}=0$.

The $\zeta$-potential and conductance of these surfactant solutions were measured, and the results are reported in
Table 1 for comparison. The value of the $\zeta$-potential can indicate the stability of nanoparticle dispersions, as nanoparticle solutions are typically not stable when the $\zeta$-potential value of the solution is close to zero. ${ }^{41,42}$ Pure CTAB micelles carry positive charges with a relative $\zeta$-potential value of around $+60.9 \mathrm{mV}$. By increasing the concentration of $\mathrm{NaOL}$ in the solution, mixed micelles were formed, and the $\zeta$-potential of the micelles decreased. This is mainly due to the charge neutralization of the $\mathrm{CTAB}$ micelles by the addition of oppositely charged $\mathrm{NaOL}$ to the mixture. The $\zeta$-potential values suddenly change from +8.66 to $-68.6 \mathrm{mV}$ by changing $\alpha_{\text {CTAB }}$ from 0.5 to 0.4 , respectively. This shows that there is a critical concentration or molar ratio in this range at which the $\zeta$-potential becomes zero and the nanoparticles in this solution are quite unstable.

The trend of conductance versus $\alpha_{\mathrm{CTAB}}$ also shows a maximum at around $\alpha_{\mathrm{CTAB}}=0.4$. As a result of charge neutralization, the degree of counterion dissociation increases and more counterions $\left(\mathrm{Br}^{-}\right.$and $\left.\mathrm{Na}^{+}\right)$, which contribute to the conductance, are freed to the solution. This does not affect the surface tension of the solution because the starting CTAB and $\mathrm{NaOL}$ solutions have concentrations much higher than their CMC values. This maximum was expected to appear at $\alpha_{\mathrm{CTAB}}$ $=0.5$ instead of 0.4 . However, the presence of a double bond in the hydrocarbon tail of $\mathrm{NaOL}$ and its conformational restriction may have some effects on the accommodation of these molecules in the mixed micelles, and thus, the double bond shifted the maximum to lower $\alpha_{\text {СТАВ }}$ values.

Figure 2 shows the TEM images of $\mathrm{Pd}$ nanoparticles synthesized by the recipes reported in Table 1 . Nanocubes with an average size of $24.1 \pm 3.4 \mathrm{~nm}$ were synthesized in the seed solution, as shown in Figure 2 (seeds). Nanocubes with an average size of $56.7 \pm 6.0 \mathrm{~nm}$ were synthesized when the seed solution was injected in the surfactant solution with only $\mathrm{CTAB}$, following the standard procedure, ${ }^{1,2}$ as shown in Figure $2\left(\alpha_{\mathrm{CTAB}}=1\right)$. However, as the CTAB molar ratio decreased in the growth solution, nanodendrites were synthesized instead of nanocubes, as seen in Figure $2\left(\alpha_{\mathrm{CTAB}}=0.9-0.5\right)$. The diameter of these $\mathrm{Pd}$ nanodendrites ranges from 45 to $66 \mathrm{~nm}$. It was also observed that some of the $\mathrm{Pd}$ seed nanocubes remained in the center of $\mathrm{Pd}$ nanodendrites, visible by the different contrast in the TEM, which is highlighted with red arrows for $\alpha_{\mathrm{CTAB}}=0.9$ and is also visible for $\alpha_{\mathrm{CTAB}}=0.8-0.5$ in Figure 2. When the СТАВ ratio decreased further $\left(\alpha_{\mathrm{CTAB}}<\right.$ $0.5)$, the $\mathrm{Pd}$ nanocubes from the seed solution and much 


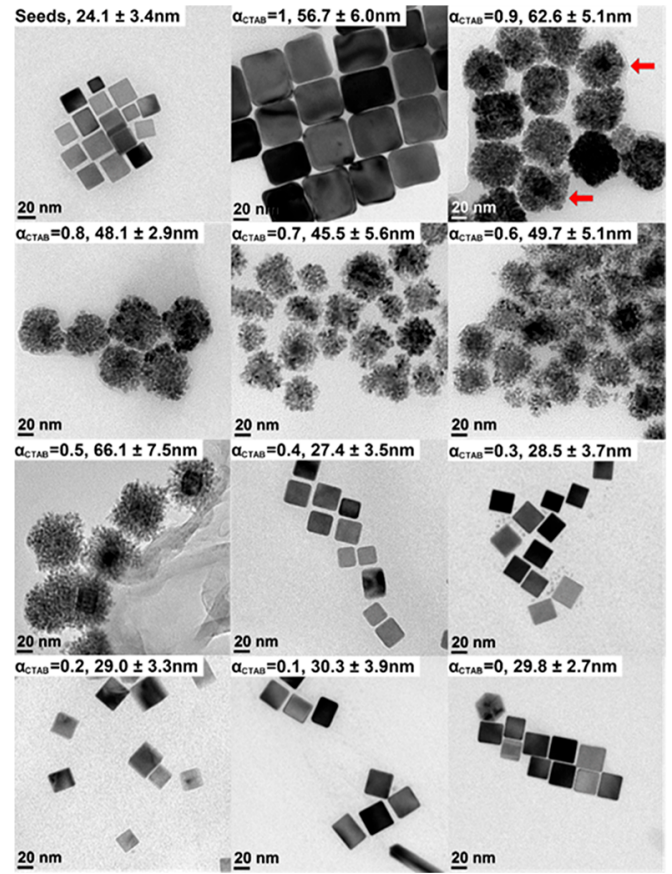

Figure 2. TEM micrographs of the Pd seeds and the Pd nanoparticles synthesized at various $\alpha_{\text {СтАв }}$ values. $\alpha_{\text {СтАВ }}$ and the average particle size of each sample are marked on the top of each image.

smaller crystals were observed; however, no larger nanoparticles or nanodendrites could be found in the samples, as seen in Figure $2\left(\alpha_{\mathrm{CTAB}}=0.4-0\right)$. This indicates that, when $\alpha_{\text {CTAB }}$ is lower than 0.5 , it becomes inefficient for reduced $\mathrm{Pd}^{0}$ to grow at the surface of the Pd seeds, and thus, small crystals are formed. This illustrates that CTAB molecules, with cationic head groups, are essential for the growth of Pd nanoparticles. When the concentration of CTAB is lower than a critical concentration $\left(\alpha_{\mathrm{CTAB}}<0.5\right)$, the $\zeta$-potential of the surfactant mixture becomes negative and no more growth is observed. Additionally, as $\alpha_{\text {СТАB }}$ approaches 0.5 , the yield of $\mathrm{Pd}$ nanodendrites decreases significantly. Due to the apparent scattering of the Pd nanodendrites, we were able to track the absorbance spectra of $\mathrm{Pd}$ nanoparticles in growth solutions with different $\alpha_{\mathrm{CTAB}}$, and the results are shown in Figure S1 of the Supporting Information.

By comparison of all tested molar ratios, it is evident that the Pd nanodendrites are stable $(\zeta \text {-potential }>30 \mathrm{mV})^{43}$ in the growth solution and with the highest yield and narrowest size distribution, as seen in Figure 2, when the value of $\alpha_{\text {СТАB }}$ is between 0.8 and 0.9 .

We performed additional structural studies of the Pd nanodendrites, shown in Figure 3. A low-magnification TEM image of the $\mathrm{Pd}$ nanodendrites $\left(\alpha_{\mathrm{CTAB}}=0.8\right)$ is shown in Figure $3 \mathrm{a}$, which illustrates that the size distribution of these nanodendrites is narrow. The selected area electron diffraction pattern (Figure $3 b$ ) of the whole area in Figure 3a clearly reveals the diffraction from $\mathrm{Pd}$ polycrystalline structures and verifies that the nanodendrites only consist of metallic $\mathrm{Pd}$ crystals. In order to observe the dendritic crystals clearly, a high-resolution TEM image was taken from a small nanodendrite without the seed (diameter $22.7 \mathrm{~nm}$ ) in Figure 3c, and its corresponding fast furious transform (FFT) image is shown in Figure 3d. Even though there are multiple dendrites, the diffraction pattern in FFT displays a Pd single-crystal

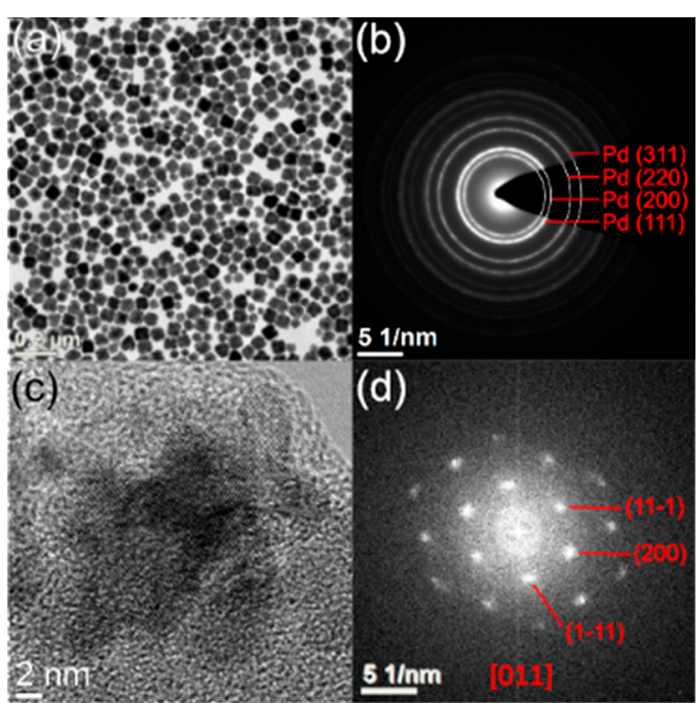

Figure 3. (a) A low-magnification TEM image of Pd nanodendrites $\left(\alpha_{\text {СтАв }}=0.8\right)$. (b) Selected area electron diffraction pattern of Pd nanodendrites. (c) High-resolution TEM image of a nanodendrite. (d) FFT image of panel c.

characterization. It illustrates that the crystal lattices of the dendrites in this nanodendrite are in the same order.

In order to investigate the formation mechanism of $\mathrm{Pd}$ nanodendrites, the growth solution $\left(\alpha_{\mathrm{CTAB}}=0.8\right)$ was monitored using the TEM and UV-vis spectroscopy at various time intervals throughout the synthesis process (14 h). TEM images can be used to show the structures that were formed throughout the growth process, and the results are displayed in Figure 4. At the beginning of the process, small Pd crystals grew rapidly on the surface of Pd seeds (Figure 4, $0 \mathrm{~h}$ ), and the size $(30.8 \pm 4.9 \mathrm{~nm})$ is approximately the same as the previously observed seeds (Figure 2, seeds). After $1 \mathrm{~h}$, nanodendrites were significantly more advanced, and the size

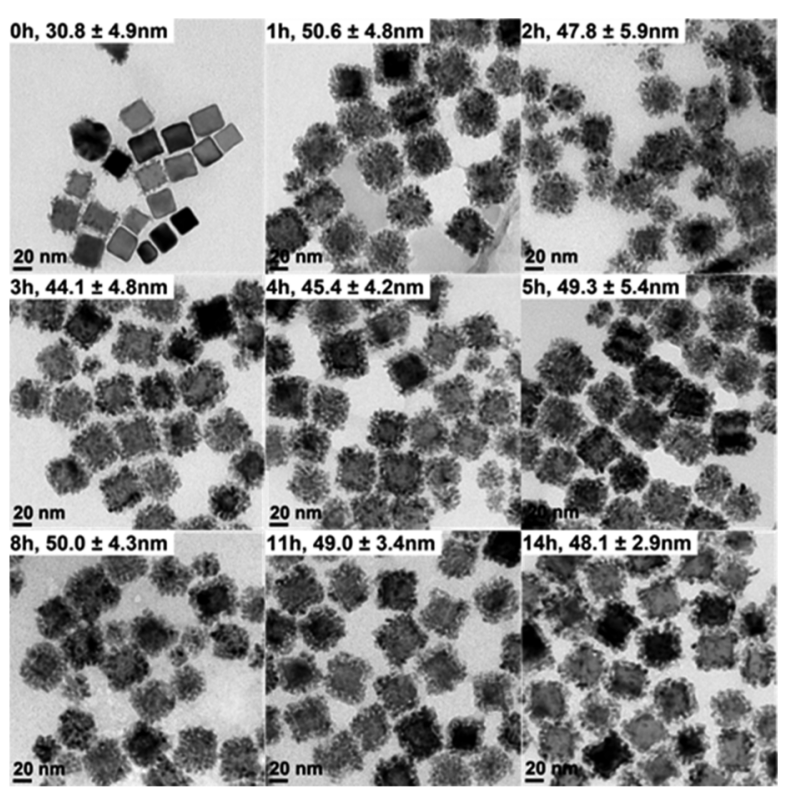

Figure 4. TEM images of Pd nanodendrites with $\alpha_{\mathrm{CTAB}}=0.8$ tracked through the growth process, indicated by hours $(\mathrm{h})$. The growth time and the average size of $\mathrm{Pd}$ nanodendrites are marked in the top right of the images. 
grew to its maximum $(50.6 \pm 4.8 \mathrm{~nm})$ in Figure $4(1 \mathrm{~h})$. Over the next several hours, the size and shape of the nanodendrites stabilized and no considerable change in shape or size, only the distribution, could be observed from Figure 4 (from 2 to $14 \mathrm{~h}$ ). UV-vis results are shown in Figure S2 of the Supporting Information. The changes observed in the kinetic UV-vis absorbance spectra corresponded well to TEM results.

It is clear that the binary surfactant mixture plays an important role in the reduction of $\mathrm{Pd}^{2+}$ ions and the shapecontrolled growth processes. Therefore, surfactant mixtures with different $\alpha_{\text {СтАВ }}$ were studied with UV-vis spectroscopy to determine if there were significant changes within the surfactant mixtures themselves that would contribute to the formation of, or lack of, nanodentritic structures. The absorbance spectra and pictures of surfactant mixture solutions are shown in Figure S3 of the Supporting Information. The results demonstrate that the phase separation occurred in the solutions with $\alpha_{\mathrm{CTAB}}=0.2-0.6$. In general, cationic and anionic surfactant mixtures show precipitation, instability, or formation of vesicles or lamellar liquid crystals when the proportion is relatively close to $1: 1 .^{44}$ The phase separation leads to a reduction of the surfactant concentrations in solutions, which decreases the efficiency of $\mathrm{Pd}$ nanoparticle growth.

Ion-pairing and neutralization of oppositely charged surfactants can also occur in the solution. As a result, some of the molecules may precipitate from the solution, especially when the Krafft temperature $\left(T_{\mathrm{K}}\right)$ of the surfactants is above room temperature. The $T_{\mathrm{K}}$ values of $\mathrm{CTAB}$ and $\mathrm{NaOL}$ are around room temperature, at 24.5 and $20{ }^{\circ} \mathrm{C}$, respectively (Table 2). ${ }^{45,46,50}$ The solubilization of ionic surfactants

Table 2. The CMC, $T_{\mathrm{K}}$, and Hydrophilic-Lipophilic Balance (HLB) Values of CTAB, NaOL, and NaST

$\begin{array}{cccc} & \mathrm{CMC}, \mathrm{mM}\left(\text { measurement temp, }{ }^{\circ} \mathrm{C}\right) & \mathrm{T}_{\mathrm{K}},{ }^{\circ} \mathrm{C} & \mathrm{HLB} \\ \mathrm{CTAB} & 0.9(25)^{34,35} & 24.5^{45} & 21.4^{35} \\ \mathrm{NaOL} & 0.4(25)^{34,35} & 20^{46} & 18^{47} \\ & 2.15(30)^{48} & & \\ \mathrm{NaST} & 1.8(30)^{48} & 79^{46} & 18^{49}\end{array}$

increases dramatically at their $T_{\mathrm{K}}$. At temperatures lower than $T_{\mathrm{K}}$, the surfactant molecules tend to precipitate from the solution (i.e., the free energy of the crystalline state is higher than the free energy of micellar solution). ${ }^{51}$ Thus, in practice, surfactants should be used at or above their $T_{\mathrm{K}}$. Therefore, Pd nanoparticles were prepared in $\mathrm{CTAB}$ and $\mathrm{NaOL}$ micellar solutions at $40{ }^{\circ} \mathrm{C}$.

It should be also noted that with the addition of inorganic salts or surfactants with opposite charge to the micellar solution, the $T_{\mathrm{K}}$ of the mixture increases. The $T_{\mathrm{K}}$ of a binary mixture of ionic surfactants with oppositely charged head groups is usually higher than the $T_{\mathrm{K}}$ of the individual surfactants and the surfactant mixture has a higher tendency to precipitate in the solution at temperatures lower than its $T_{\mathrm{K}}$. Moreover, the trend of hydrophilic-lipophilic balance (HLB) as a function of $\mathrm{CTAB}-\mathrm{NaOL}$ micellar composition has a minimum at $\alpha_{\mathrm{CTAB}}=0.5 .^{35}$ This shows that these oppositely charged surfactants are strongly attracted to each other in the solution and their aggregation behavior is nonideal and strongly synergistic.

The results of the $\mathrm{Pd}$ nanodendrites synthesized at various $\alpha_{\mathrm{CTAB}}$ and surfactant mixture solutions suggest that the formation of the dendritic shape is affected by the adsorption of the CTAB and NaOL molecules on the seed surfaces. The surface tension, aggregation number of surfactants in micelles, and CPPs are among the most critical parameters affecting the growth of nanoparticles. The CMC values of CTAB and NaOL at $25{ }^{\circ} \mathrm{C}$ are 0.9 and $0.4 \mathrm{mM}$, respectively, as shown in Table $2 .^{34,35}$ However, the mixtures of these two surfactants have lower CMC values than the individual surfactants. The lowest $\mathrm{CMC}\left(0.2 \mathrm{mM}\right.$ at $\left.25^{\circ} \mathrm{C}\right)$ exists for a mixture with a molar ratio equal to $1 .^{34,35}$ The concentration of surfactants used in our experiments $(50 \mathrm{mM})$ is nearly 50 times higher than the $C M C$ values of any of the individual surfactants. Therefore, the $\mathrm{CTAB}$ and $\mathrm{NaOL}$ mixtures form micelles in the growth solutions and adsorb on the surface of Pd nanoparticle seeds. Additionally, the surface tensions of all growth solutions remain relatively constant. ${ }^{34,35}$ It is known that the pure Pd seed surface is hydrophilic and negatively charged. ${ }^{52-54}$ When only $\mathrm{CTAB}$ was used in the growth solution $\left(\alpha_{\mathrm{CTAB}}=1\right)$, $\mathrm{CTAB}$ molecules formed a continuous double layer on the surface of Pd seeds. ${ }^{53,54}$ However, on the basis of the theory of surfactant adsorption on a hydrophilic surface, the addition of $\mathrm{NaOL}$ breaks the CTAB double layer through the electrostatic interaction of these two surfactants and forms mixed micelles on the Pd seed surfaces instead, leading to a decrease of the interaction between surfactants and the Pd seed surface. ${ }^{36}$ The shape of the mixed micelles is affected by the CPP values of $\mathrm{CTAB}$ and $\mathrm{NaOL}$. Additionally, Pd precursors tend to exist as $\mathrm{PdCl}_{4}{ }^{2-}$, a negatively charged ion. ${ }^{40}$ Therefore, Pd precursors are attracted to the $\mathrm{Pd}$ seed surface with $\mathrm{CTAB}$ and repulsed by the addition of the $\mathrm{NaOL}$ molecules. In other words, CTAB attracts the $\mathrm{Pd}$ precursor ions to reduce into $\mathrm{Pd}$ atoms and deposit on the seed surface, but $\mathrm{NaOL}$ does not favor this, resulting in the initial formation of small $\mathrm{Pd}$ clusters in the solution, which can deposit on the seed surface where the surfactant layer is attractive to these clusters.

On the basis of the aforementioned discussion, we put forward a model for the formation of Pd nanodendrites: with the addition of $\mathrm{NaOL}$ in the growth solutions, $\mathrm{Pd}^{2+}$ ions were first reduced to form small Pd crystals in mixed surfactant micelles and then these Pd crystals were adsorbed on the Pd seed surfaces through the interaction between the surfactants and surfaces. Because the Pd seed surfaces and Pd precursors are negatively charged, anionic $\mathrm{NaOL}$ has a much weaker interaction with the Pd seed surfaces than the cationic CTAB, leading to the deposition of small Pd crystals on the seed surface with CTAB molecules. Therefore, the interactions between the mixed surfactant micelles and $\mathrm{Pd}$ seed surfaces decreased as the concentration of $\mathrm{NaOL}$ increased. When the concentration of $\mathrm{NaOL}$ was higher than a critical value $\left(\alpha_{\text {СТАB }}\right.$ $\leq 0.4)$, small Pd crystals were not able to adsorb on the seed surfaces. The results in Figure 2 and $\zeta$-potential values in Table 1 correlate well to this model. The dendrites of each particle at $\alpha_{\text {CTAB }} \geq 0.5$ are small and show crystalline-particle shapes. Pd seeds injected in growth solutions of $\alpha_{\text {СТАВ }} \leq 0.4$ do not grow further. Additionally, the $\zeta$-potential becomes negative at the critical value $\left(\alpha_{\mathrm{CTAB}} \leq 0.4\right)$.

In order to test this model, Pd nanoparticles were grown without adding seeds in the growth solutions. Then the Pd nanodendrite solutions were centrifuged at 9700 RCF for 40 min to precipitate all sizes of Pd nanoparticles. TEM images of the nanoparticles from four growth solutions without seeds are shown in Figure 5. When $\alpha_{\mathrm{CTAB}}=1$, irregular shapes of $\mathrm{Pd}$ nanoparticles were formed instead of the uniform cubic shape. 


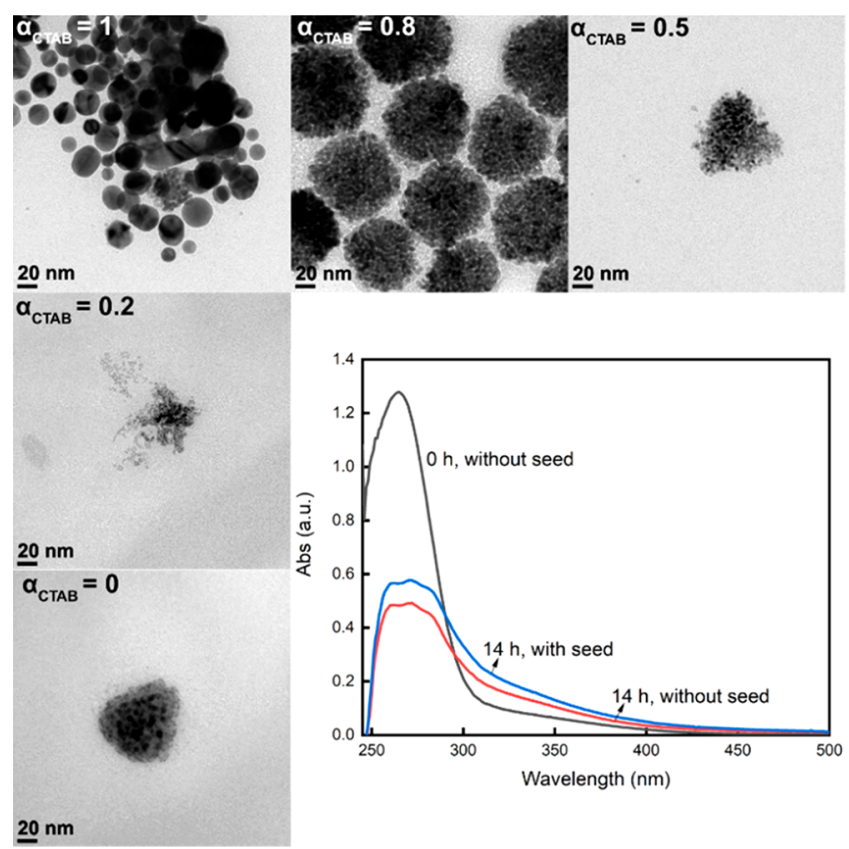

Figure 5. TEM images of Pd nanoparticles grown without seeds. $\alpha_{\mathrm{CTAB}}$ is marked on the top left of each image. Absorbance spectra for the growth solutions with $\alpha_{\mathrm{CTAB}}=0$.

This is probably because CTAB molecules form micelles instead of a continuous double layer in the solution without Pd seeds as the cubic solid template. In the same growth process with seeds, there is also a small percentage of nanoparticles with irregular shapes, which were washed away by centrifugation. When $\alpha_{\mathrm{CTAB}}=0.8$, high-yield Pd nanodendrites were still obtained. However, when $\alpha_{\mathrm{CTAB}}=0.5,0.2$ and 0 , much smaller crystals and fewer small crystal aggregations were found. This result illustrates that $\mathrm{Pd}^{2+}$ ions in these solutions were reduced to $\mathrm{Pd}^{0}$ successfully and formed small $\mathrm{Pd}$ crystals. These small crystals aggregated to form nanodendrites when $\alpha_{\mathrm{CTAB}}=0.8$, but they were not able to aggregate when $\alpha_{\mathrm{CTAB}}=$ $0.5,0.2$, and 0 . Additionally, the absorbance spectra when $\alpha_{\text {CTAB }}=0$, shown in Figure 5, also confirmed this. The intensity of the peak at $\lambda=265 \mathrm{~nm}$ from $\mathrm{H}_{2} \mathrm{PdCl}_{4}$ decreased drastically from 0 to $14 \mathrm{~h}$ in the growth solution without seeds. In addition, a broad peak at $\lambda=272 \mathrm{~nm}$, from $\mathrm{Pd}^{0}$, was formed, which is at the same wavelength as the peak in the growth solution with seeds. Therefore, we assess that the $\mathrm{Pd}^{2+}$ ions were reduced by AA and formed small Pd crystals in both growth solutions with and without seeds. These results from Figure 5 also support the suggested model.

The observation of small Pd crystals in the growth solutions without seeds shows that $\mathrm{Pd}^{2+}$ ions were reduced and formed small crystals initially. Then, the aggregation of these crystals is determined by the surfactant composition. When $\alpha_{\mathrm{CTAB}}=1$, $\mathrm{Pd}$ nanocubes grow from Pd cubic seeds; when $0.5 \leq \alpha_{\mathrm{CTAB}} \leq$ $0.9, \mathrm{Pd}$ nanodendrites and a few Pd crystals are obtained; and when $0 \leq \alpha_{\mathrm{CTAB}} \leq 0.4$, small Pd crystals are formed and $\mathrm{Pd}$ seeds are not able to grow. The three different situations are illustrated in the scheme of Figure 1.

It is demonstrated above that Pd nanodendrites were formed

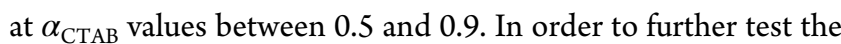
importance of each surfactant in the solutions and the effects of other growth parameters, such as stirring, temperature, and $\mathrm{pH}$ value, several experiments were set for the Pd nanodendrite synthesis at one of the most effective molar ratios $\left(\alpha_{\text {СтАв }}=\right.$ $0.8)$.

First, the possibility of replacing $\mathrm{CTAB}$ or $\mathrm{NaOL}$ by another surfactant with a similar structure was considered. Since the $\mathrm{Br}^{-}$ions influence on the formation of the $\{100\}$ facets, ${ }^{55}$ the substitution of $\mathrm{Br}^{-}$by $\mathrm{Cl}^{-}$ions possibly alters the dendritic shape. Additionally, the carbon-carbon double bond in $\mathrm{NaOL}$ molecules affects the physical properties, so the replacement of the double bond can also potentially change the dendritic shape. In our first experiment, CTAC was used instead of $\mathrm{CTAB}$ in the synthesis. Pd nanodendrites were synthesized successfully using this synthesis procedure, as seen in Figure 6a. These Pd nanodendrites have a comparable size (65.2 \pm

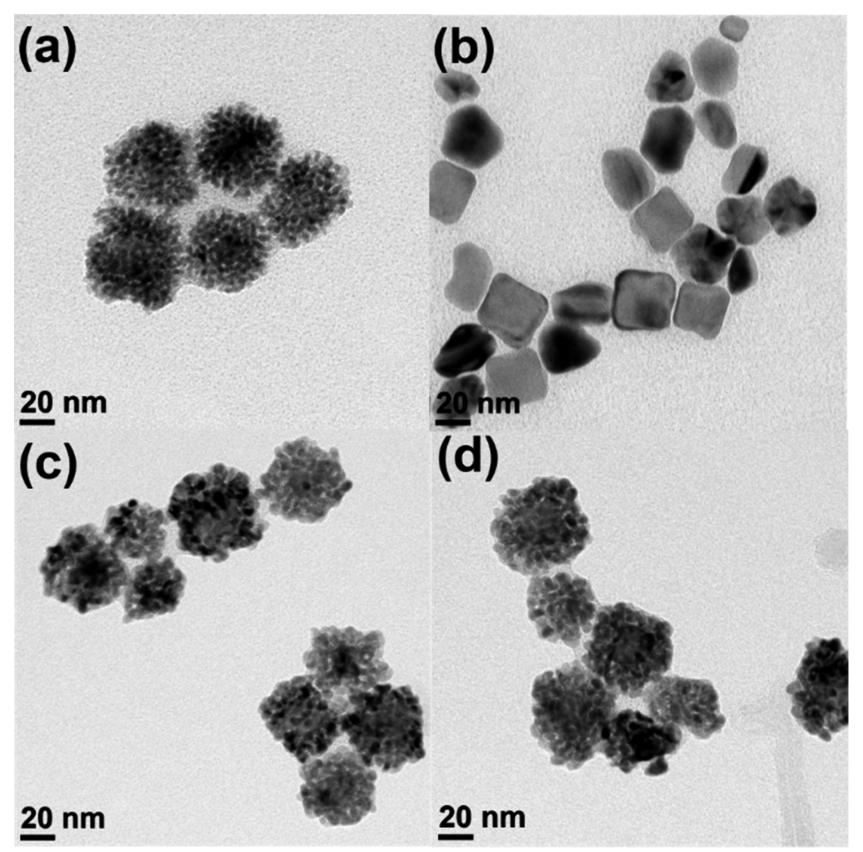

Figure 6. TEM images with different magnifications: (a) Pd nanodendrites synthesized by CTAC and $\mathrm{NaOL}$, (b) Pd nanoparticles synthesized by $\mathrm{CTAB}$ and $\mathrm{NaST}$, (c) Pd nanodendrites synthesized by stirring the growth solution for $10 \mathrm{~min}$, and (d) Pd nanodendrites synthesized by stirring the growth solution for the whole $14 \mathrm{~h}$.

$6.1 \mathrm{~nm}$ ) and appear to have a dendritic structure similar to that of the $\mathrm{CTAB}-\mathrm{NaOL} \mathrm{Pd}$ nanodendrites with the same molar ratio $\left(\alpha_{\mathrm{CTAB}}=0.8\right.$ in Figure 2$)$. Therefore, the dendritic shape of $\mathrm{Pd}$ nanoparticles was not affected when $\mathrm{Br}^{-}$ions were replaced by $\mathrm{Cl}^{-}$ions and CTAC molecules played the same role as the CTAB molecules. This illustrates that $\mathrm{CTA}^{+}$is a crucial part of the formation of nanodendrites. In the second experiment, $\mathrm{NaOL}$ was replaced by $\mathrm{NaST}$, which has a similar structure as $\mathrm{NaOL}$ but lacks the double bond in the hydrocarbon tail. We observed that the dendritic shape could not be achieved when using $\mathrm{NaST}$, as shown in Figure $6 \mathrm{~b}$. Even though the only difference in chemical structure between the $\mathrm{NaOL}$ and $\mathrm{NaST}$ molecules is the double bond, the lack of a double bond in the hydrocarbon tail increases the $T_{\mathrm{K}}$ of NaST $\left(79{ }^{\circ} \mathrm{C}\right.$ in Table 2). Therefore, NaST has a lower solubility in the growth solution at the reaction temperature $\left(40{ }^{\circ} \mathrm{C}\right)$. However, the barely soluble $\mathrm{NaST}$ molecules still interrupt the formation of $\mathrm{Pd}$ nanocubes. This indicates that the double bond in the $\mathrm{NaOL}$ hydrocarbon tail affects the formation of the dendritic shape. 
We also investigated several other parameters that are often adjusted in nanoparticle growth synthesis, beginning with the stirring of the solution during the growth process, which affects the uniformity of surfactants and other reactants in the solution. Three comparative experiments were set up for $\alpha_{\mathrm{CTAB}}$ $=0.8$ : no stirring, as seen in Figure $2\left(\alpha_{\mathrm{CTAB}}=0.8\right)$; stirring for $10 \mathrm{~min}$, followed by still incubation for the remainder of the growth period, as seen in Figure 6c; and stirring for the entire $14 \mathrm{~h}$ growth period, as seen in Figure 6d. These experiments all resulted in the formation of the Pd nanodendrites, and this illustrates that the stirring does not affect the formation or shape of the Pd nanodentrites.

The temperature and $\mathrm{pH}$ value of the growth solutions are two other important parameters to tune the shape and size of nanoparticles, as well as affecting the surfactants in the solution. Therefore, we compared growth temperatures of 40 , 60 , and $80{ }^{\circ} \mathrm{C}$. We also tuned the $\mathrm{pH}$ value (6.4) of the growth solution before the reduction step to $\mathrm{pH} 5.4$ by adding a small amount of $\mathrm{HCl}$ solution and to $\mathrm{pH} 7.3$ by adding a small amount of $\mathrm{NaOH}$ solution. The TEM images and average sizes are shown in Figure 7. In order to compare the size and shape

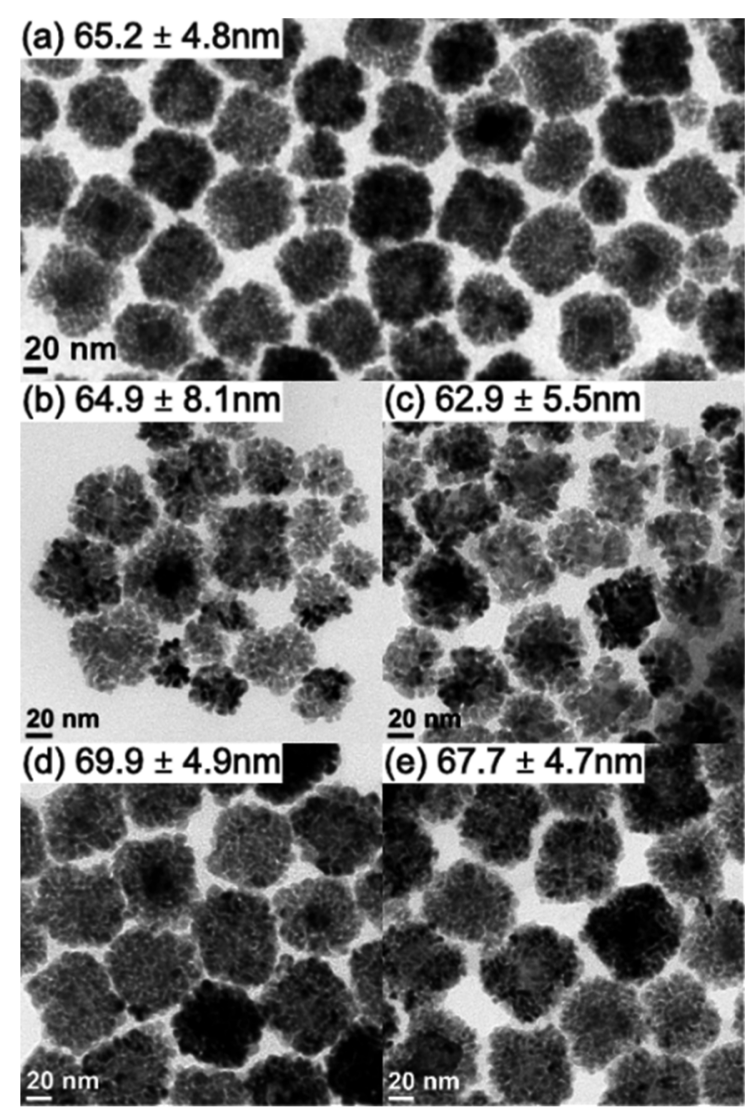

Figure 7. TEM images of Pd nanodendrites: (a) growth at $40{ }^{\circ} \mathrm{C}$ with original pH 6.4, (b) growth at $60^{\circ} \mathrm{C}$ with $\mathrm{pH} 6.4$, (c) growth at $80^{\circ} \mathrm{C}$ with $\mathrm{pH} 6.4,(\mathrm{~d})$ growth at $40{ }^{\circ} \mathrm{C}$ with $\mathrm{pH} 5.4$, and (e) growth at 40 ${ }^{\circ} \mathrm{C}$ with $\mathrm{pH}$ 7.3.

precisely, we also set a growth at $40{ }^{\circ} \mathrm{C}$ without tuning the $\mathrm{pH}$ as a standard. Pd nanodendrites were synthesized successfully in all growth solutions. TEM images are shown in Figure 7. The average size of $\mathrm{Pd}$ nanodendrites synthesized at $40{ }^{\circ} \mathrm{C}$ without tuning the $\mathrm{pH}$ is $65.2 \pm 4.8 \mathrm{~nm}$, as shown in Figure $7 \mathrm{a}$. As the growth temperature increased, the average size decreased slightly $\left(64.9 \pm 8.1 \mathrm{~nm}\right.$ at $60{ }^{\circ} \mathrm{C}$ and $62.9 \pm 5.5$ $\mathrm{nm}$ at $80^{\circ} \mathrm{C}$ ) and the size distribution broadened, as shown in Figure $7 \mathrm{~b}, \mathrm{c}$. However, compared to Figure $7 \mathrm{a}$, the TEM images in Figure $7 b, c$ show that the small nanocrystals that form the dendritic structure are larger at higher growth temperature. It is because the higher temperature increased the reaction rate of the growth of the small Pd nanocrystals, leading to the formation of larger nanocrystals and some Pd nanodendrites without seeds. The seedless Pd nanodendrites are usually smaller than those with seeds, which makes the size distribution wider. Additionally, the higher yield of seedless nanodendrites uses the $\mathrm{Pd}$ source and the size of $\mathrm{Pd}$ nanodendrites with seeds decreases. When the $\mathrm{pH}$ is adjusted, as seen in Figure $7 \mathrm{~d}, \mathrm{e}$, the sizes of Pd nanodendrites (69.9 \pm $4.9 \mathrm{~nm}$ at $\mathrm{pH} 5.4$ and $67.7 \pm 4.7 \mathrm{~nm}$ at $\mathrm{pH} 7.3$ ) are slightly larger than those in the original solution at $\mathrm{pH} 6.4$, as shown in Figure $7 \mathrm{a}$. However, the size distribution and the dendritic shape do not change significantly. The studies in Figure 7 demonstrate that the temperature and $\mathrm{pH}$ value do not influence the formation of the dendritic structure but can be used to influence the size and dispersity of the $\mathrm{Pd}$ nanodendrites.

\section{CONCLUSIONS}

In this work, Pd nanodendrites were successfully synthesized with binary surfactant mixtures of $\mathrm{CTAB}$ and $\mathrm{NaOL}$ in different molar ratios. The optimal value of $\alpha_{\mathrm{CTAB}}$ is between 0.8 and 0.9 , with which Pd nanodendrites with the highest yield and narrowest size distribution were obtained. The molar ratio of CTAB in the growth solutions governs the shapes of the Pd nanoparticles. Pd nanocubes are formed with $\alpha_{\mathrm{CTAB}}=1$. For $0.5 \leq \alpha_{\mathrm{CTAB}}<1$, Pd crystals aggregate to form nanodendrites. When $\alpha_{\mathrm{CTAB}}<0.5$, Pd crystals are not able to aggregate, resulting in no growth of $\mathrm{Pd}$ seeds.

Our proposed model for the formation of $\mathrm{Pd}$ nanodendrites is that the addition of $\mathrm{NaOL}$ breaks the continuous CTAB double layer and leads to the formation of mixed surfactant micelles on Pd seed surfaces by the electrostatic interaction. $\mathrm{Pd}^{2+}$ ions are reduced to form small crystals in the mixed surfactant micelles and then the crystals are adsorbed on Pd seed surfaces, depending on the interaction between the surfactants and the Pd seed surfaces. As the concentration of $\mathrm{NaOL}$ increases, this interaction decreases. When $\alpha_{\text {CTAB }}$ is lower than 0.4, the interaction is too weak to promote aggregation, leading to no growth of the Pd seeds.

$\mathrm{CTA}^{+}$and $\mathrm{OL}^{-}$ions play a significant role in the formation of the nanodendrites. Pd nanodendrites can be synthesized successfully with both CTAB or CTAC in this method but cannot be synthesized when replacing $\mathrm{NaOL}$ with $\mathrm{NaST}$. As the growth temperature increased, the size of $\mathrm{Pd}$ nanodendrites decreased and the size distribution was wider. Additionally, the size of $\mathrm{Pd}$ nanodendrite was also influenced by the $\mathrm{pH}$ value. However, the stirring of the growth solution does not affect the dendritic shape. Additionally, the growth of Pd nanodendrites proceeds mainly in the first hour and the nanodendrites stabilize in the remainder of the growth time.

These nanodedritic structures will be of significant further interest in catalytic and sensing applications due to their increased surface area and high-index facets present in the nanodentrites. 


\section{ASSOCIATED CONTENT}

\section{(5) Supporting Information}

The Supporting Information is available free of charge at https://pubs.acs.org/doi/10.1021/acs.langmuir.9b03804.

Characterization of $\mathrm{Pd}$ nanoparticle solutions and surfactant solutions by UV-vis spectroscopy, a highresolution TEM image of $\mathrm{Pd}$ nanodendrites, and histograms of the size distribution of Pd nanoparticles (Figures S1-S9) (PDF)

\section{AUTHOR INFORMATION}

\section{Corresponding Author}

Kasper Moth-Poulsen - Department of Chemistry and Chemical Engineering, Chalmers University of Technology, SE412-96 Gothenburg, Sweden; (1) orcid.org/0000-0003-40184927; Email: kasper.moth-poulsen@chalmers.se

\section{Authors}

Xin Wen - Department of Chemistry and Chemical Engineering, Chalmers University of Technology, SE-412-96 Gothenburg, Sweden; (1) orcid.org/0000-0002-4325-3054

Sarah Lerch - Department of Chemistry and Chemical Engineering, Chalmers University of Technology, SE-412-96 Gothenburg, Sweden; 이이이.org/0000-0001-5968-8178

Zhihang Wang - Department of Chemistry and Chemical Engineering, Chalmers University of Technology, SE-412-96 Gothenburg, Sweden; 이이이.org/0000-0002-9961-3346

Bassem Aboudiab - Baha and Walid Bassatne Department of Chemical Engineering and Advanced Energy, American University of Beirut, Beirut 1107-2020, Lebanon

Ali Reza Tehrani-Bagha - Baha and Walid Bassatne Department of Chemical Engineering and Advanced Energy, American University of Beirut, Beirut 1107-2020, Lebanon; ๑ orcid.org/0000-0002-8206-3827

Eva Olsson - Department of Physics, Chalmers University of Technology, SE-412-96 Gothenburg, Sweden; (1) orcid.org/ 0000-0002-3791-9569

Complete contact information is available at: https://pubs.acs.org/10.1021/acs.langmuir.9b03804

\section{Author Contributions}

The manuscript was written through contributions of all authors. All authors have given approval to the final version of the manuscript.

\section{Notes}

The authors declare no competing financial interest.

\section{ACKNOWLEDGMENTS}

We acknowledge financial support from the Knut and Alice Wallenberg Foundation, the European Research Council (ERC) and the Swedish Research Council. We thank Prof. Martin Andersson for fruitful discussions. We also thank Dr. Robson Rosa Da Silva and Jessica Orrego Hernandez for their suggestions on experiments.

\section{REFERENCES}

(1) Niu, W.; Zhang, L.; Xu, G. Shape-Controlled Synthesis of SingleCrystalline Palladium Nanocrystals. ACS Nano 2010, 4 (4), 19871996.

(2) Niu, W.; Li, Z.-Y.; Shi, L.; Liu, X.; Li, H.; Han, S.; Chen, J.; Xu, G. Seed-Mediated Growth of Nearly Monodisperse Palladium
Nanocubes with Controllable Sizes. Cryst. Growth Des. 2008, 8 (12), 4440-4444.

(3) Jewell, L. L.; Davis, B. H. Review of Absorption and Adsorption in the Hydrogen-palladium System. Appl. Catal., A 2006, 310, 1-15.

(4) Yamauchi, M.; Ikeda, R.; Kitagawa, H.; Takata, M. Nanosize Effects on Hydrogen Storage in Palladium. J. Phys. Chem. C 2008, 112 (9), 3294-3299.

(5) Watson, G. W.; Wells, R. P. K.; Willock, D. J.; Hutchings, G. J. A Comparison of the Adsorption and Diffusion of Hydrogen on the $\{111\}$ Surfaces of Ni, Pd, and Pt from Density Functional Theory Calculations. J. Phys. Chem. B 2001, 105 (21), 4889-4894.

(6) Conrad, H.; Ertl, G.; Latta, E. E. Adsorption of Hydrogen on Palladium Single Crystal Surfaces. Surf. Sci. 1974, 41, 435-446.

(7) Johnson, N. J. J.; Lam, B.; MacLeod, B. P.; Sherbo, R. S.; Moreno-Gonzalez, M.; Fork, D. K.; Berlinguette, C. P. Facets and Vertices Regulate Hydrogen Uptake and Release in Palladium Nanocrystals. Nat. Mater. 2019, 18, 454-458.

(8) Li, G.; Kobayashi, H.; Dekura, S.; Ikeda, R.; Kubota, Y.; Kato, K.; Takata, M.; Yamamoto, T.; Matsumura, S.; Kitagawa, H. Shapedependent Hydrogen-storage Properties in Pd Nanocrystals: Which Does Hydrogen Prefer, Octahedron (111) or Cube (100)? J. Am. Chem. Soc. 2014, 136 (29), 10222-10225.

(9) Kim, S.; Lee, D.-W.; Lee, K.-Y. Shape-dependent Catalytic Activity of Palladium Nanoparticles for the Direct Synthesis of Hydrogen Peroxide from Hydrogen and Oxygen. J. Mol. Catal. A: Chem. 2014, 391, 48-54.

(10) Huang, X.; Neretina, S.; El-Sayed, M. A. Gold Nanorods: From Synthesis and Properties to Biological and Biomedical Applications. Adv. Mater. 2009, 21, 4880-4910.

(11) Ahmed, S.; Ahmad, M.; Swami, B. L.; Ikram, S. A Review on Plants Extract Mediated Synthesis of Silver Nanoparticles for Antimicrobial Applications: A Green Expertise. Journal of Advanced Research 2016, 7 (1), 17-28.

(12) Sau, T. K.; Rogach, A. L. Nonspherical Noble Metal Nanoparticles: Colloid-Chemical Synthesis and Morphology Control. Adv. Mater. 2010, 22 (16), 1781-1804.

(13) Zhang, X.; Yin, H.; Wang, J.; Chang, L.; Gao, Y.; Liu, W.; Tang, Z. Shape-dependent Electrocatalytic Activity of Monodispersed Palladium Nanocrystals toward Formic Acid Axidation. Nanoscale 2013, 5, 8392-8397.

(14) Huang, Y.; Dai, L.; Song, L.; Zhang, L.; Rong, Y.; Zhang, J.; Nie, Z.; Chen, T. Engineering Gold Nanoparticles in Compass Shape with Broadly Tunable Plasmon Resonances and High-Performance SERS. ACS Appl. Mater. Interfaces 2016, 8, 27949-27955.

(15) Zhou, Y.; Zeng, H. C. Kinetically Controlled Growth of Fine Gold Nanofractals from $\mathrm{Au}(\mathrm{I})$ via Indirect Galvanic Replacement Reaction. ACS Appl. Mater. Interfaces 2015, 7, 21552-21561.

(16) Zhou, Y.; Zeng, H. C. Simultaneous Synthesis and Assembly of Noble Metal Nanoclusters with Variable Micellar Templates. J. Am. Chem. Soc. 2014, 136, 13805-13817.

(17) Niu, W.; Zhang, L.; Xu, G. Seed-mediated Growth of Noble Metal Nanocrystals: Crystal Growth and Shape Control. Nanoscale 2013, 5, 3172-3181.

(18) Murphy, C. J.; Sau, T. K.; Gole, A. M.; Orendorff, C. J.; Gao, J.; Gou, L.; Hunyadi, S. E.; Li, T. Anisotropic Metal Nanoparticles: Synthesis, Assembly, and Optical Applications. J. Phys. Chem. B 2005, 109 (29), 13857-13870.

(19) Jana, N. R.; Gearheart, L.; Murphy, C. J. Seed-mediated Growth Approach for Shape-controlled Synthesis of Spheroidal and Rod-like Gold Nanoparticles Using a Surfactant Template. Adv. Mater. 2001, 13, 1389-1393.

(20) Ibupoto, Z. H.; Khun, K.; Liu, X.; Willander, M. Low Temperature Synthesis of Seed Mediated CuO Bundle of Nanowires, Their Structural Characterisation and Cholesterol Detection. Mater. Sci. Eng., C 2013, 33 (7), 3889-3898.

(21) Dai, L.; Song, L.; Huang, Y.; Zhang, L.; Lu, X.; Zhang, J.; Chen, $\mathrm{T}$. Bimetallic $\mathrm{Au} / \mathrm{Ag}$ Core-Shell Superstructures with Tunable Surface Plasmon Resonance in the Near-Infrared Region and High Perform- 
ance Surface-Enhanced Raman Scattering. Langmuir 2017, 33, 53785384

(22) Yang, Y.; Song, L.; Huang, Y.; Chen, K.; Cheng, Q.; Lin, H.; Xiao, P.; Liang, Y.; Qiang, M.; Su, F.; Chen, T. Asymmetrical Molecular Decoration of Gold Nanorods for Engineering of ShapeControlled AuNR@Ag Core-Shell Nanostructures. Langmuir 2019, 35, 16900-16906.

(23) Nikoobakht, B.; El-Sayed, M. A. Preparation and Growth Mechanism of Gold Nanorods (NRs) Using Seed-Mediated Growth Method. Chem. Mater. 2003, 15 (10), 1957-1962.

(24) Wang, Y.-N.; Wei, W.-T.; Yang, C.-W.; Huang, M. H. SeedMediated Growth of Ultralong Gold Nanorods and Nanowires with a Wide Range of Length Tunability. Langmuir 2013, 29 (33), 1049110497.

(25) Bastús, N. G.; Comenge, J.; Puntes, V. Kinetically Controlled Seeded Growth Synthesis of Citrate-stabilized Gold Nanoparticles of up to $200 \mathrm{~nm}$ : Size Focusing versus Ostwald Ripening. Langmuir 2011, 27 (17), 11098-11105.

(26) Johnson, C. J.; Dujardin, E.; Davis, S. A.; Murphy, C. J.; Mann, S. Growth and Form of Gold Nanorods Prepared by Seed-mediated, Surfactant-directed Synthesis. J. Mater. Chem. 2002, 12, 1765-1770.

(27) Lattuada, M.; Hatton, T. A. Functionalization of Monodisperse Magnetic Nanoparticles. Langmuir 2007, 23 (4), 2158-2168.

(28) Wiley, B.; Sun, Y.; Mayers, B.; Xia, Y. Shape-controlled Synthesis of Metal Nanostructures: The Case of Silver. Chem. - Eur. J. 2005, 11 (2), 454-463.

(29) Grzelczak, M.; Perez-Juste, J.; Mulvaney, P.; Liz-Marzan, L. M. Shape Control in Gold Nanoparticle Synthesis. Chem. Soc. Rev. 2008, 37, 1783-1791.

(30) Chen, S.; Carroll, D. L. Silver Nanoplates: Size Control in Two Dimensions and Formation Mechanisms. J. Phys. Chem. B 2004, 108 (18), 5500-5506.

(31) Chen, H.; Shao, L.; Li, Q.; Wang, J. Gold Nanorods and Their Plasmonic Properties. Chem. Soc. Rev. 2013, 42 (7), 2679-2724.

(32) Sun, L.; Song, Y.; Wang, L.; Guo, C.; Sun, Y.; Liu, Z.; Li, Z. Ethanol-induced Formation of Silver Nanoparticle Aggregates for Highly Active SERS Substrates and Application in DNA Detection. J. Phys. Chem. C 2008, 112 (5), 1415-1422.

(33) Chang, G.; Oyama, M.; Hirao, K. Facile Synthesis of Monodisperse Palladium Nanocubesand the Characteristics of Selfassembly. Acta Mater. 2007, 55, 3453-3456.

(34) El Kadi, N.; Martins, F.; Clausse, D. 1.; Schulz, P. C. Critical Micelle Concentrations of Aqueous Hexadecytrimethylammonium Bromide-sodium Oleate Mixtures. Colloid Polym. Sci. 2003, 281, 353362.

(35) Miraglia, D. B.; Rodríguez, J. L.; Minardi, R. M.; Schulz, P. C. Critical Micelle Concentration and HLB of the Sodium OleateHexadecyltrimethylammonium Bromide Mixed System. J. Surfactants Deterg. 2011, 14, 401-408.

(36) Kronberg, B.; Holmberg, K.; Lindman, B. Surface Chemistry of Surfactants and Polymers; Wiley, 2014.

(37) Ye, X.; Zheng, C.; Chen, J.; Gao, Y.; Murray, C. B. Using Binary Surfactant Mixtures to Simultaneously Improve the Dimensional Tunability and Monodispersity in the Seeded Growth of Gold Nanorods. Nano Lett. 2013, 13 (2), 765-771.

(38) Ye, X.; Gao, Y.; Chen, J.; Reifsnyder, D. C.; Zheng, C.; Murray, C. B. Seeded Growth of Monodisperse Gold Nanorods Using Bromide-Free Surfactant Mixtures. Nano Lett. 2013, 13, 2163-2171.

(39) Ye, X.; Jin, L.; Caglayan, H.; Chen, J.; Xing, G.; Zheng, C.; Doan-Nguyen, V.; Kang, Y.; Engheta, N.; Kagan, C. R.; Murray, C. B. Improved Size-Tunable Synthesis of Monodisperse Gold Nanorods throughthe Use of Aromatic Additives. ACS Nano 2012, 6 (3), 28042817.

(40) Huang, Y.; Ferhan, A. R.; Dandapat, A.; Yoon, C. S.; Song, J. E.; Cho, E. C.; Kim, D.-H. A Strategy for the Formation of GoldPalladium Supra-Nanoparticles from Gold Nanoparticles of Various Shapes and Their Application to High-Performance $\mathrm{H}_{2} \mathrm{O}_{2}$ Sensing. J. Phys. Chem. C 2015, 119, 26164-26170.
(41) Jiang, J.; Oberdorster, G.; Biswas, P. Characterization of Size, Surface Charge, and Agglomerationstate of Nanoparticle Dispersions for Toxicological Studies. J. Nanopart. Res. 2009, 11, 77-89.

(42) Bhattacharjee, S. DLS and Zeta Potential-What They Are and What They Are Not? J. Controlled Release 2016, 235, 337-351.

(43) Xu, R.; Wu, C.; Xu, H. Particle Size and Zeta Potential of Carbon Black in Liquid Media. Carbon 2007, 45 (14), 2806-2809.

(44) Kume, G.; Gallotti, M.; Nunes, G. Review on Anionic/Cationic Surfactant Mixtures. J. Surfactants Deterg. 2008, 11 (1), 1-11.

(45) Manojlovic, J. Ž. The Krafft Temperature of Surfactant Solutions. Thermal Science 2012, 16, 631-640.

(46) McBain, J. W.; Sierichs, W. C. The Solubility of Sodium and Potassium Soaps and the Phase Diagrams of Aqueous Potassium Soaps. J. Am. Oil Chem. Soc. 1948, 25 (6), 221-225.

(47) Mukerjee, P.; Mysels, K. J. Critical Micelle Concentrations of Aqueous Surfactant Systems; U.S. Government Printing Office: Washington, DC, 1970.

(48) Akhter, M. S. Effect of Acetamide on the Critical Micelle Concentration of Aqueous Solutions of Some Surfactants. Colloids Surf., A 1997, 121 (2-3), 103-109.

(49) Pluciński, P. K. The Influence of Solubilization upon the Permeation of Aromatic Hydrocarbons through Liquid Membranes. J. Membr. Sci. 1985, 23, 105-109.

(50) Moroi, Y.; Matuura, R.; Kuwamura, T.; Inokuma, S.-I. Anionic Surfactants with Divalent Gegenions of Separate Electric Charge: Solubility and Micelle Formation. J. Colloid Interface Sci. 1986, 113 (1), 225-231.

(51) Wolfrum, S. Long Chain Soaps and Alkyl Sulfates in Aqueous Solutions at Room Temperature. Doctoral Thesis, University of Regensburg, 2017.

(52) Louie, S. G. Electronic Statesand Adsorbate-induced Photoemission Structure on the Pd (111) Surface. Phys. Rev. Lett. 1978, 40 (23), 1525-1528.

(53) Wei, Z.; Matsui, H. Rational Strategy for Shaped Nanomaterial Synthesis in Reverse Micelle Reactors. Nat. Commun. 2014, 5, 3870.

(54) Sun, Y.; Zhang, L.; Zhou, H.; Zhu, Y.; Sutter, E.; Ji, Y.; Rafailovich, M. H.; Sokolov, J. C. Seedless and Templateless Synthesis of Rectangular Palladium Nanoparticles. Chem. Mater. 2007, 19 (8), 2065-2070.

(55) Peng, H.-C.; Xie, S.; Park, J.; Xia, X.; Xia, Y. Quantitative Analysis of the Coverage Density of Br- Ions on $\operatorname{Pd}\{100\}$ Facets and Its Role in Controlling the Shape of Pd Nanocrystals. J. Am. Chem. Soc. 2013, 135 (10), 3780-3783. 